\title{
Effect of Passive Film on Cavitation Corrosion Behavior of 316L Stainless Steel
}

\author{
Lifang Cao ${ }^{1}$, Zhenbo Qin ${ }^{1}$, Yida Deng ${ }^{1}$, Cheng Zhong ${ }^{1}$, Wenbin $H u^{1,2}$, Zhong $W u^{1, *}$ \\ ${ }^{1}$ Tianjin Key Laboratory of Composite and Functional Materials, School of Material Science and \\ Engineering, Tianjin University, Tianjin 300072, China \\ ${ }^{2}$ Key Laboratory of Advanced Ceramics and Machining Technology (Ministry of Education), Tianjin \\ University, Tianjin 300072, China \\ *E-mail: wuzhong2319@163.com
}

doi: $10.20964 / 2020.01 .51$

Received: 5 October 2019/ Accepted: 11 November 2019 / Published: 30 November 2019

\begin{abstract}
The effect of passive film on the cavitation erosion-corrosion of 316L stainless steel (316L SS) was investigated via pulse and continuous cavitation modes, open circuit potential (OCP) measurements and scanning electron microscope (SEM). Results demonstrate that the passive film healed rapidly within seconds during pulse cavitation in $3.5 \mathrm{wt} \% \mathrm{NaCl}$ solution and played an important role in resisting the cavitation erosion-corrosion. 316L SS exhibition negative synergistic characteristic between cavitation erosion and corrosion due to its optimal repassivation performance in the absence of cavitation erosion.
\end{abstract}

Keywords: 316L stainless steel; cavitation erosion-corrosion; synergism; electrochemical; passive film

\section{$\underline{\text { FULL TEXT }}$}

(C) 2020 The Authors. Published by ESG (www.electrochemsci.org). This article is an open access article distributed under the terms and conditions of the Creative Commons Attribution license (http://creativecommons.org/licenses/by/4.0/). 